\title{
Longitudinal lung function decline and wood dust exposure in the furniture industry
}

\author{
G. Jacobsen*,\#, V. Schlünssen\#", I. Schaumburg*, E. Taudorf and T. Sigsgaard"
}

\begin{abstract}
The aim of the present study was to investigate the relationship between change in lung function and cumulative exposure to wood dust.
\end{abstract}

In total, 1,112 woodworkers (927 males, 185 females) and 235 reference workers (104 males, 185 females) participated in a 6-yr longitudinal study. Forced expiratory volume in one second (FEV1), forced vital capacity (FVC), height and weight were measured, and questionnaire data on respiratory symptoms, wood dust exposure and smoking habits were collected. Cumulative inhalable wood dust exposure was assessed using a study-specific job exposure matrix and exposure time.

The median (range) for cumulative wood dust exposure was $3.75(0-7.55) \mathrm{mg} \cdot \mathrm{year} \cdot \mathrm{m}^{-3}$. A doseresponse relationship between cumulative wood dust exposure and percent annual decrease in FEV1 was suggested for female workers. This was confirmed in a linear regression model adjusted for confounders, including smoking, height and age. An additional difference of $-14.50 \mathrm{~mL} \cdot \mathrm{yr}^{-1}$ and $-27.97 \mathrm{~mL} \cdot \mathrm{yr}^{-1}$ was revealed for females exposed to $3.75-4.71 \mathrm{mg} \cdot \mathrm{yr} \cdot \mathrm{m}^{-3}$ or to $>4.71 \mathrm{mg} \cdot \mathrm{yr} \cdot \mathrm{m}^{-3}$, respectively, compared with non-/low-exposed females. For females, a positive trend between wood dust exposure and the cumulative incidence proportion of $\mathrm{FEV}_{1} / \mathrm{FVC}<\mathbf{7 0} \%$ was suggested.

In conclusion, in the present low-exposed cohort, female woodworkers had an accelerated decline in lung function, which may be clinically relevant.

KEYWORDS: Cohort, dust, lung function in epidemiology, occupational, sex, wood pproximately 3.6 million workers in the European Union are exposed to wood dust [1]. Wood dust has long been associated with a variety of respiratory symptoms, including asthma, chronic bronchitis and rhinoconjunctivitis. The majority of knowledge is based on cross-sectional studies performed during the past 30 yrs.

Previous studies describing the relationship between chronic obstructive pulmonary disease (COPD) and exposure to wood dust have shown conflicting results: while a number of studies have shown an association between decreased lung function and wood dust exposure [2-4], others found no such association [5-8].

Most previous studies describe associations between lung function (e.g. forced expiratory volume in one second (FEV1), forced vital capacity (FVC), FEV1/FVC) and current exposure $[2,4-6]$. Some studies have used cumulative exposure indexes to evaluate differences in baseline lung function $[3,7,8]$.

In the baseline study preceding the present follow-up study, SCHLÜNSSEN et al. [9] found a significant association between inhalable dust concentration and percentage fall in FEV1 during the workday for woodworkers using pine. However, no association was found between current exposure to wood dust or seniority, and lung function.

Until now, no follow-up studies have been performed in the dry wood industry to which the furniture industry belongs. A few follow-up studies on sawmills processing western red cedar wood have suggested an accelerated decline in lung function in relation to wood dust exposure $[3,10]$. Western red cedar is the only type of wood that has been thoroughly studied and it has been revealed that a special compound (plicatic acid) is a causal agent for asthma among exposed workers.

Exposure assessments in the wood industry have either been based on studies of available exposure measurements sampled for other purposes, and not performed as a part of the epidemiological study, or assessments have been made based on qualitative data supplemented by a limited number of measurements. In addition, most previous studies have been carried out on
AFFILIATIONS

*Dept of Occupational Medicine,

Region Hospital Skive, Skive,

\#Dept of Occupational and Environmental Medicine, Institute of Public Health, Århus University, Århus, and

"Dept of Respiratory Medicine, Hilleroed Hospital, Hilleroed, Denmark.

\section{CORRESPONDENCE}

G. Jacobsen

Dept of Occupational Medicine

Region Hospital Skive

Resenvej 25

7800 Skive

Denmark

Fax: 4589274879

E-mail: gitte.jacobsen@

sygehusviborg.dk

Received:

November 102006

Accepted after revision:

October 262007

SUPPORT STATEMENT

The study was supported by the Danish Work Environment

Foundation, Viborg County, The Danish Medical Research Council, The Health Insurance Fund and The Danish Lung Association.

STATEMENT OF INTEREST

None declared.

European Respiratory Journal

Print ISSN 0903-1936

Online ISSN 1399-3003 
relatively small study populations, where confounding variables such as smoking, height and age could not be dealt with sufficiently.

In Denmark, it has been estimated that $\sim 70,000$ workers $(3.3 \%$ of the working population) are occupationally exposed to wood dust. One of the largest groups, the furniture industry employs 15,000 workers [1, 11]. In the Danish furniture industry, the wood types processed are mainly softwood, predominantly pine wood and wood composites, e.g. particleboard and medium density fibreboard. In total, $>80 \%$ are employed at factories with $>20$ employees [11].

The aim of the present follow-up study was to investigate the relationship between decline in lung function and cumulative exposure to wood dust in order to ascertain whether accelerated decline in lung function could be revealed among subjects exposed to wood dust in the Danish furniture industry.

\section{MATERIALS AND METHODS Study population}

The baseline study population was identified in a crosssectional study performed from 1997-1998, and is described elsewhere [9]. In brief, 86 factories with $>4$ employees situated in Viborg County, Denmark were identified. All factories with $>20$ employees were asked to participate (45 of 48 accepted) and, additionally, a random sample of factories with 5-20 employees (9 of 38 accepted) was drawn. A total of 54 factories participated in the study. The study population was workers employed in the woodworking departments, assembly departments and stock departments of these factories. Additionally three factories (two producing refrigerators and one producing hearing aids) were selected in the same area as reference. Reference workers were chosen from departments where only mechanical assembly was performed.

In total, 1,819 woodworkers and 415 control subjects returned a questionnaire and participated with a valid lung function test at baseline. They were defined as the population for follow-up. Follow-up took place from 2003-2005. Visits to 52 furniture factories (38 participated at baseline) and three control factories resulted initially in establishing contact to 846 individuals from the exposed group and 197 reference workers. The remaining subjects were contacted by letter and invited to a follow-up examination. In total, 1,112 (61\%) woodworkers and 235 (57\%) control subjects participated at follow-up. A flow chart of the study is shown in figure 1.

All participants gave informed consent, and the protocol was approved by the Ethics Committee for Viborg County.

\section{Exposure assessment}

Personal dust sampling was carried out at baseline and at follow-up with passive dust monitors described previously $[12,13]$. In brief, the method is based on measuring light extinction before and after sampling on transparent sticky foils. Light extinction was measured before and after sampling, reported as dust-covered foil area and converted to equivalent inhalable dust by linear regression models based on earlier and present calibration measurements $[11,13]$. In order to calculate cumulative wood dust exposure in the follow-up period, job exposure matrices (JEMs) based on factory size and task were

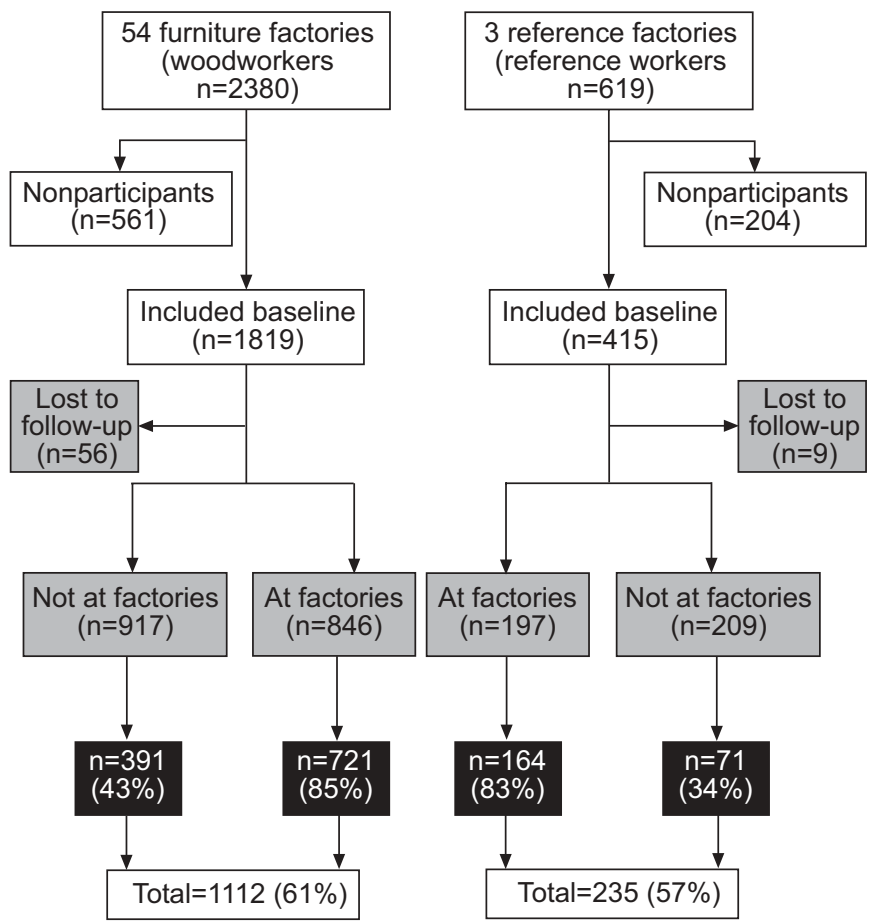

FIGURE 1. Flow chart of the study population.

constructed at baseline (12 groups, 2,217 measurements, 1,581 individuals) and at follow-up (7 groups, 1,355 measurements, 1,044 individuals). The groups were based on a random effect analysis, where grouping by task and factory size achieved the greatest contrast between groups [11, 14].

A modified British Medical Research Council questionnaire [15] with key European Community Respiratory Health Survey questions on asthma [16] and additional questions on allergy, coughing, asthma, rhinitis, smoking and occupational history, including work tasks, was distributed at baseline and follow-up [9].

Individual cumulative exposure was estimated from the exposure level at baseline for half the period (until 2001) and the exposure level at follow-up for the remaining period. In the analyses, workers were divided into groups based on the quartiles of distribution of cumulative dust exposure. Reference workers were assigned to the lowest exposure category.

\section{Measurements of lung function}

Lung function testing was performed using a dry spirometer Vitalograph $_{\mathbb{R}}$, Buckingham, UK) according to European Respiratory Society guidelines [17]. The same spirometer was used for all measurements during the first investigation and at follow-up. All measurements were conducted by the same research group of three individuals. FEV1, FVC, height and weight were measured. Only lung functions meeting the reproducibility criteria of $<200 \mathrm{~mL}$ difference between the largest and the second largest value were accepted and included in the analyses. In total, $98.6 \%$ met the criteria. At baseline, pre- and post-shift values were measured at the workplace and 313 subjects had an additional lung function 


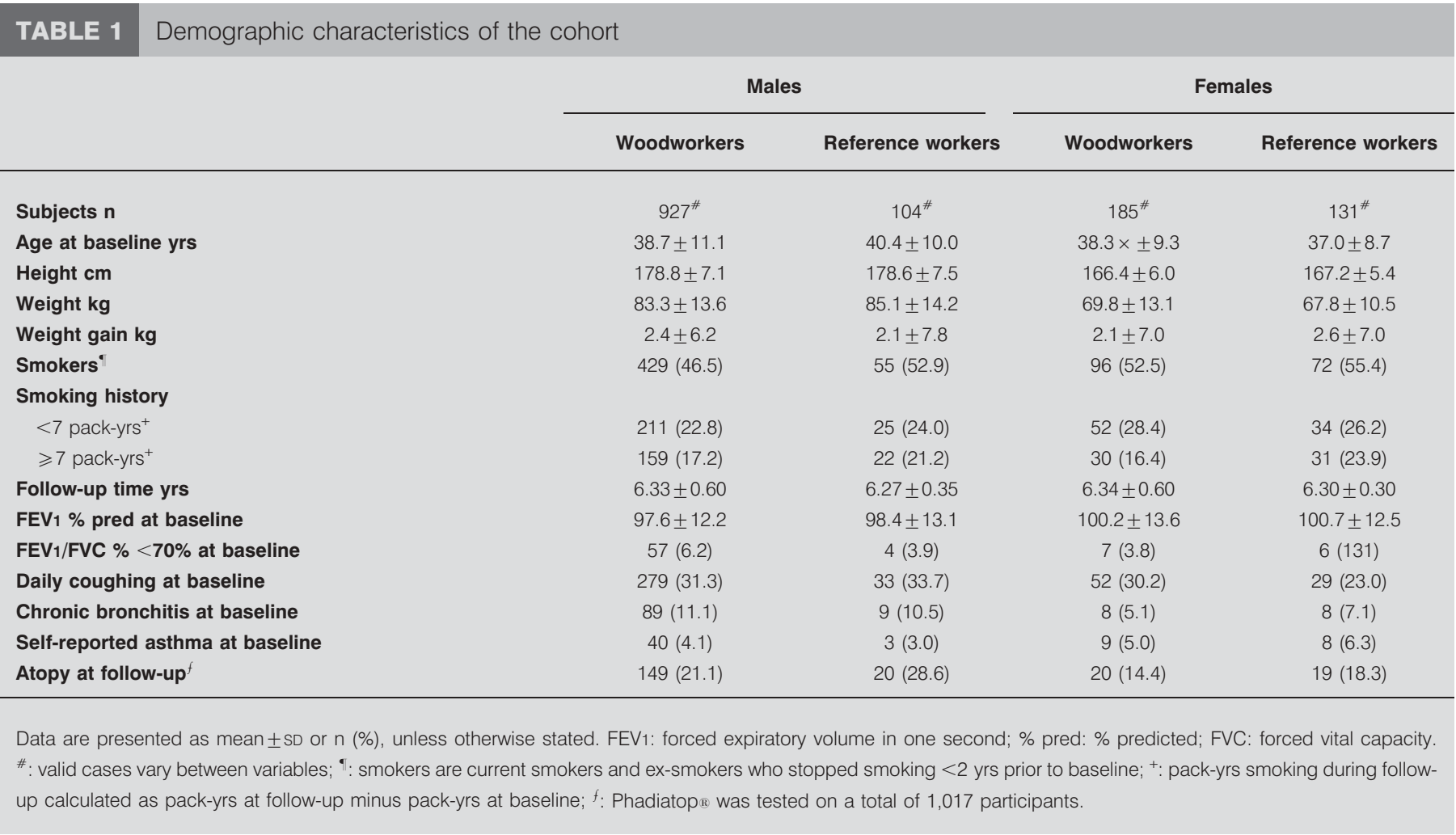

test at the hospital. At follow-up, pre-shift values were measured at factories and the remaining part of the cohort, not working at one of the factories, was invited to a lung function test. A total of 111 subjects had an additional lung function test at the hospital.

The highest FVC and FEV1 (FVCmax and FEV1, max, respectively) from all accepted lung functions at baseline were used to calculate percent of predicted values at baseline. The Danish standards for age $\geqslant 30$ yrs supplied by the Danish Society of Lung Physicians [18] were used as reference. For the group aged 15-29 yrs, a Danish reference group consisting of healthy, nonsmoking farming students [19] was used.

Absolute change in FEV1 was calculated as FEV1,max at followup minus FEV1, max at baseline. The same procedure was followed for FVC. The changes in volume at follow-up were recorded as absolute and relative change per year. The time between measurements was used to calculate change per year. Relative changes are given as absolute change per year divided by baseline values and reported as percentage change per year.

A cumulative incidence proportion (proportion of newly developed cases), of FEV1/FVC $<70 \%$ in the follow-up period (median 6.3 yrs) was used as a cut-off point for obstruction. Blood sampling was performed on a subpopulation at followup. Atopic status was available for 843 woodworkers and 174 controls, and was defined as a positive phadiatop ${ }_{\circledR}$ (specific immunoglobulin E to 12 common allergens) [20].

\section{Analysis}

When data were normally distributed, mean \pm SD were reported. When data were log-normally distributed, geometric mean (geometric SD) were stated. When data were neither normally nor log-normally distributed, median (range) were reported.

Univariate analyses and analyses stratified by sex and smoking were undertaken for categorical variables using Chi-squared tests. For continuous variables independent sample t-tests or the Mann-Whitney U-test were used. When creating the JEM, the geometric mean of the individual arithmetic mean distribution was calculated for each group. In order to compare mean changes in FEV1 and FVC in exposure groups, one-way ANOVA using Dunnett's method for multiple comparisons was used. In further analyses, association between exposure groups and absolute and relative changes in FEV1 and FVC were analysed using multiple linear regression adjusting for confounders. The cumulative incidence proportion in the follow-up period stratified by sex and smoking was analysed using Chi-squared tests. In further analyses, logistic regression adjusting for confounders was conducted. To test for trends across exposure groups, regression analyses were performed treating exposure groups as a continuous variable.

Smoking was expressed as pack-yrs in the follow-up period. For smokers, the median was 6.5 pack-yrs, therefore, 7 packyrs was used as the cut-off point between light and heavy smokers.

\section{RESULTS}

The participation rate during follow-up was $61 \%$ for woodworkers and $57 \%$ for reference workers. At baseline, participants were slightly older $(\mathrm{p}<0.05)$ compared with nonparticipants for woodworkers ( $38.7 \pm 10.8$ versus $35.8 \pm 11.9 \mathrm{yrs})$ and for 
TABLE 2 Changes in lung function of woodworkers and reference workers stratified by sex and smoking

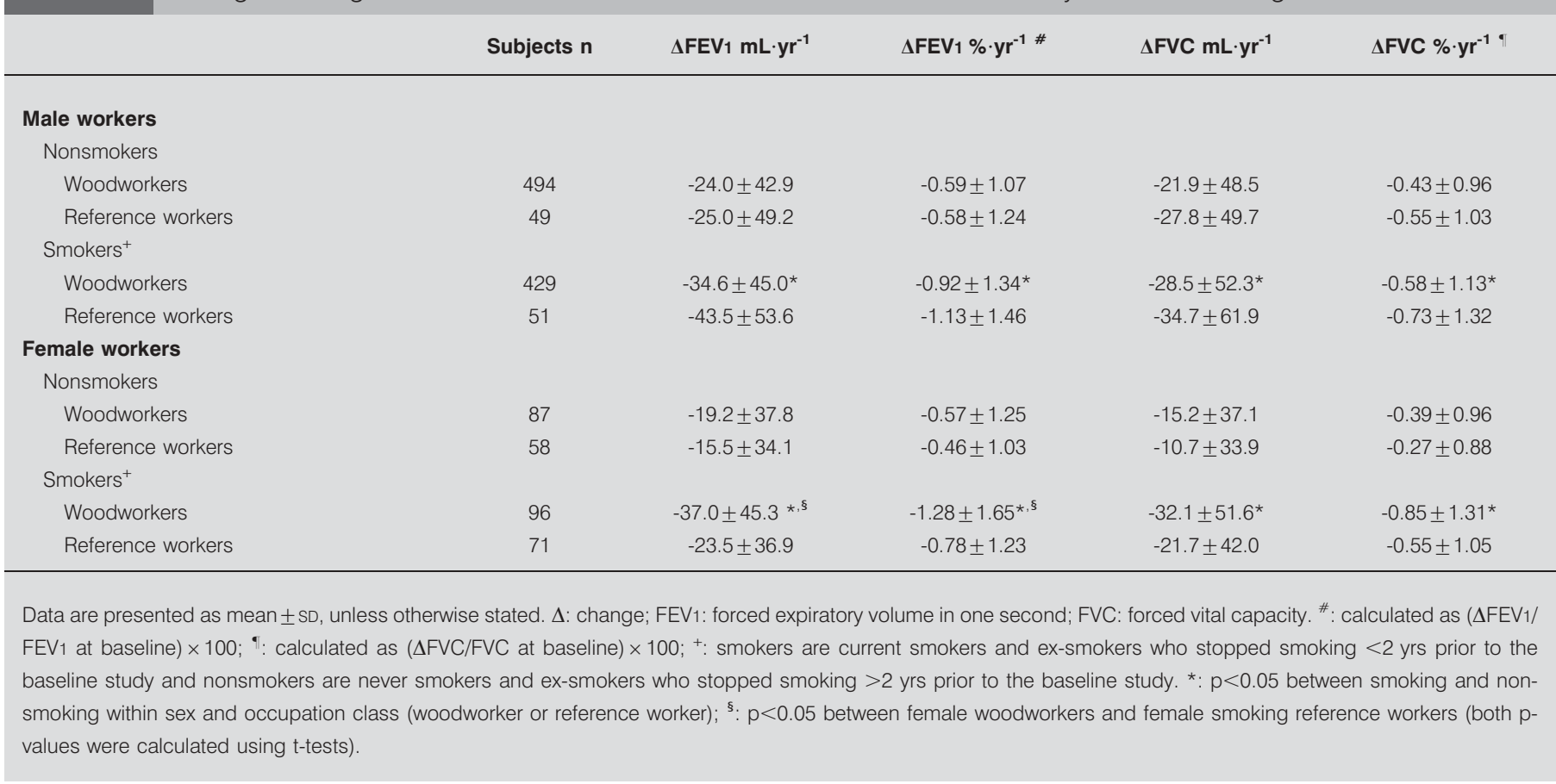

reference workers $(38.4 \pm 9.4$ versus $34.0 \pm 9.9$ yrs). More nonparticipants were smokers at baseline compared with participants for woodworkers (52.1 versus $44.3 \%$ ) and for reference workers (63.4 versus $51.8 \%$; $<<0.05$ ). In addition, nonparticipants among woodworkers tended to cough more at baseline $(\mathrm{p}<0.05)$, while no differences were found between participants

TABLE 3 Changes in lung function related to cumulative wood dust exposure stratified for sex and smoking

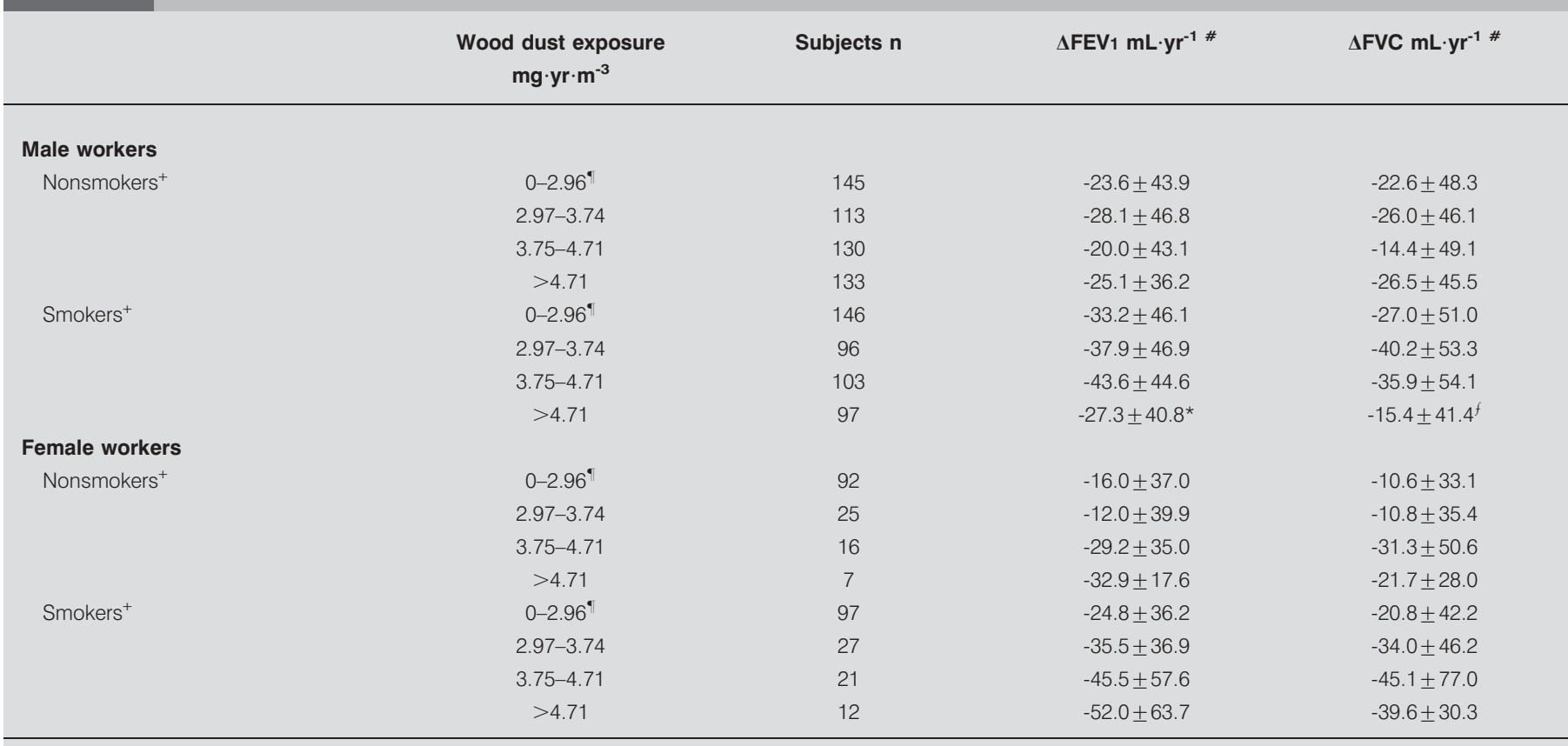

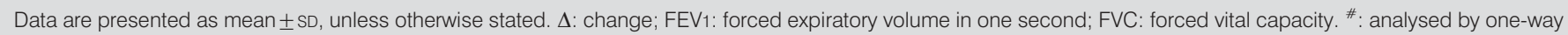
ANOVA; ": group includes reference workers; ${ }^{+}$: smokers are current smokers and ex-smokers who stopped smoking $<2$ yrs prior to the baseline study and nonsmokers are never smokers and ex-smokers who stopped smoking $>2$ yrs prior to the baseline study. *: $p<0.05$ versus male smokers in exposure group $3.75-4.71 \mathrm{mg} \cdot y r \cdot \mathrm{m}^{-3}$; $f: \mathrm{p}<0.05$ versus males smokers in exposure groups $2.97-3.75$ and $3.75-4.71 \mathrm{mg} \cdot \mathrm{yr} \cdot \mathrm{m}^{-3}$. 

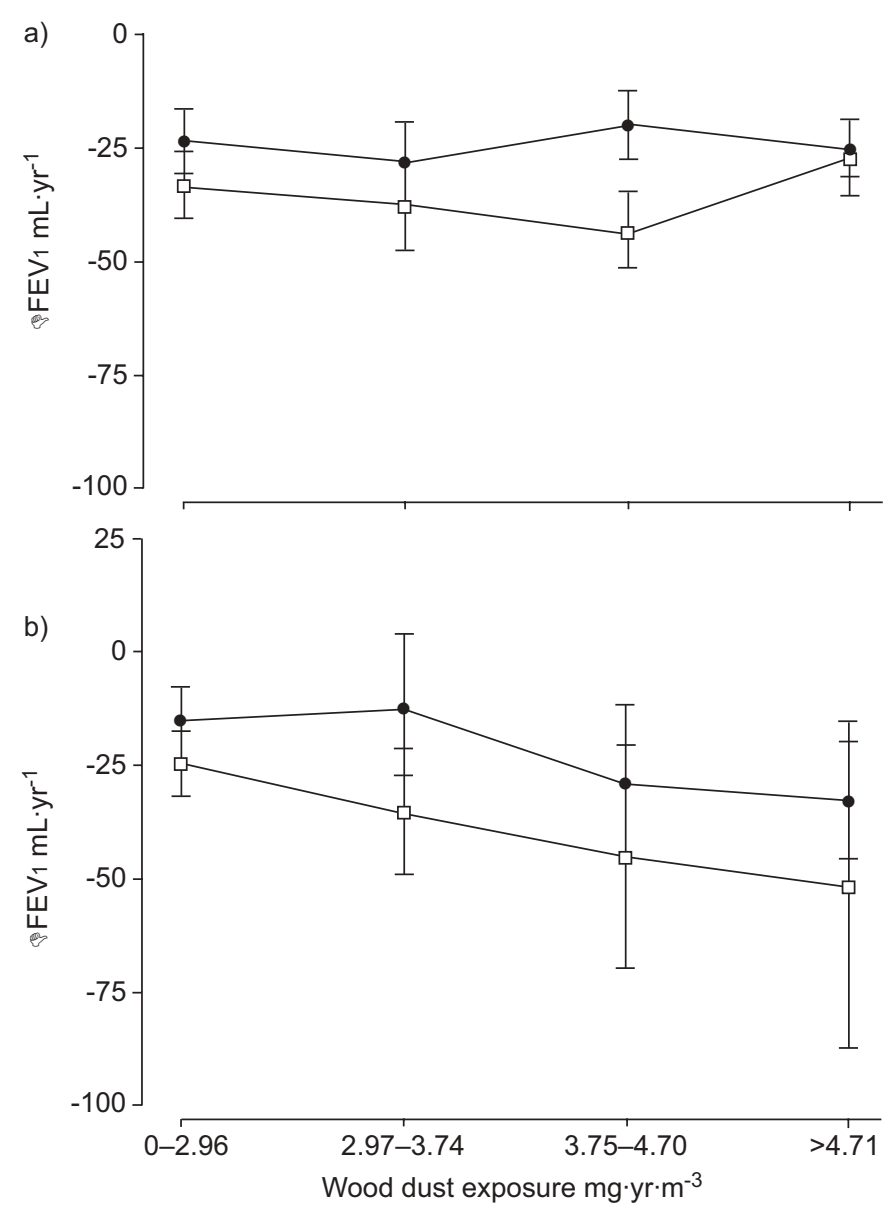

FIGURE 2. Mean annual change in forced expiratory volume in one second $\left(\triangle F E V_{1}\right)$ and cumulative wood dust exposure in a) males and b) females. $\square$ : smokers; 0 : nonsmokers. Whiskers indicate confidence intervals.

and nonparticipants for chronic bronchitis, self-reported asthma, objective measurements of lung function expressed as FEV1\% pred, or geometric mean of measured baseline wood dust exposure.

A higher percentage of both woodworkers and reference workers contacted at the factories participated compared with those invited by letter (fig. 1). Analyses for differences between woodworkers invited at the factories compared with woodworkers invited outside the factories revealed no differences in FEV1\% pred at baseline, respiratory symptoms reported at baseline (daily coughing, chronic bronchitis and self-reported asthma) or smoking habits. A significantly higher percentage of baseline bronchitis was found for reference workers who were contacted outside the factories versus reference workers still at the factories (13.6 versus $4.8 \%$; $<0.01$ ).

Table 1 lists the demographic characteristics of the cohort. Fewer females were seen among woodworkers and woodworkers smoked less than reference workers, although not significantly. Subsequently, analyses were stratified for sex and smoking. No significant differences were found in baseline symptoms or atopy between exposed workers and reference workers or between males and females. Males, however, tended to be more atopic than females.
A significant decrease in exposure was seen from the period 1997-1998 to 2003-2004. The overall geometric mean (geometric SD) at baseline among 1,682 woodworkers was $0.94 \pm 2.10 \mathrm{mg} \cdot \mathrm{yr} \cdot \mathrm{m}^{-3}$ and the corresponding values at followup among 1,044 woodworkers was $0.60 \pm 1.60 \mathrm{mg} \cdot \mathrm{yr} \cdot \mathrm{m}^{-3}$. The median (range) of cumulative wood exposure among woodworkers in the follow-up cohort was $3.75(0-7.55) \mathrm{mg} \cdot \mathrm{yr} \cdot \mathrm{m}^{-3}$. Significantly higher levels of cumulative exposure were found among woodworkers still employed in the furniture industry compared with workers who had left the industry (median (range) $4.23(0.47-7.55)$ versus $\left.2.16(0-6.64) \mathrm{mg} \cdot \mathrm{yr} \cdot \mathrm{m}^{-3}\right)$. For the age group $<55$ versus $\geqslant 55$ yrs, the difference was $3.81(0-7.55)$ versus $3.17(0-6.23) \mathrm{mg} \cdot \mathrm{yr} \cdot \mathrm{m}^{-3}$. For males versus females, the difference was $3.81(0-7.55)$ versus $3.26(0-6.87) \mathrm{mg} \cdot \mathrm{yr} \cdot \mathrm{m}^{-3}$. No difference was found in cumulative exposure estimates between smokers and nonsmokers.

At baseline, $42 \%$ of woodworkers used mainly pinewood, $13 \%$ used particleboard or fibreboards and $6 \%$ used different kinds of hard wood, mainly beech. The remaining 39\% used a mixture of different wood species.

Table 2 summarises the absolute and relative changes in FEV1 and FVC stratified by sex and smoking for woodworkers and reference workers. No significant differences were seen for male workers, but a significantly greater decline in FEV1 was seen for both absolute and relative values for smoking female woodworkers compared with reference workers.

In table 3 absolute changes of FEV1 and FVC related to cumulative exposure, stratified by sex and smoking, are presented. Analysis included reference workers in the lowest exposure group. Except for male smokers in the highest exposure group, who had a lesser decline in lung volumes, no significant differences were found for mean changes in the four exposure groups. In figure 2 the changes in FEV1 are presented graphically.

Regression analyses for the associations between cumulative dust exposure and changes in lung function revealed borderline interactions between sex and exposure for absolute changes in FEV1 and significant interactions for relative changes in FEV1 and FVC.

Table 4 presents the result of linear regression for the association between cumulative exposure and absolute changes in lung function stratified by sex and adjusted for smoking, age, height and weight-gain during follow-up. For male workers, no association between exposure and decline in lung volume was revealed, but for female workers, a significant association between exposure $>3.74 \mathrm{mg} \cdot \mathrm{yr} \cdot \mathrm{m}^{-3}$ and decline in FEV1 was found. When regression analyses were repeated treating exposure groups as a continuous variable, a significant negative trend for decline in FEV1 $(p=0.003)$ and decline in FVC $(p=0.01)$ was revealed across exposure groups for female workers. As expected, smoking was related to decline in lung function, most pronounced for heavy smokers. Adjusting for, or stratifying by, baseline respiratory symptoms (i.e. doctor-diagnosed asthma) and daily coughing at baseline in the models did not change the estimates. The analyses were repeated on the subgroup of workers where atopic status was available. Adjusting for, or stratifying by, atopy did not change the results significantly. 
TABLE 4 Association between changes in lung function and cumulative exposure of wood dust in the cohort, stratified by sex and adjusted for confounders in linear regression analyses

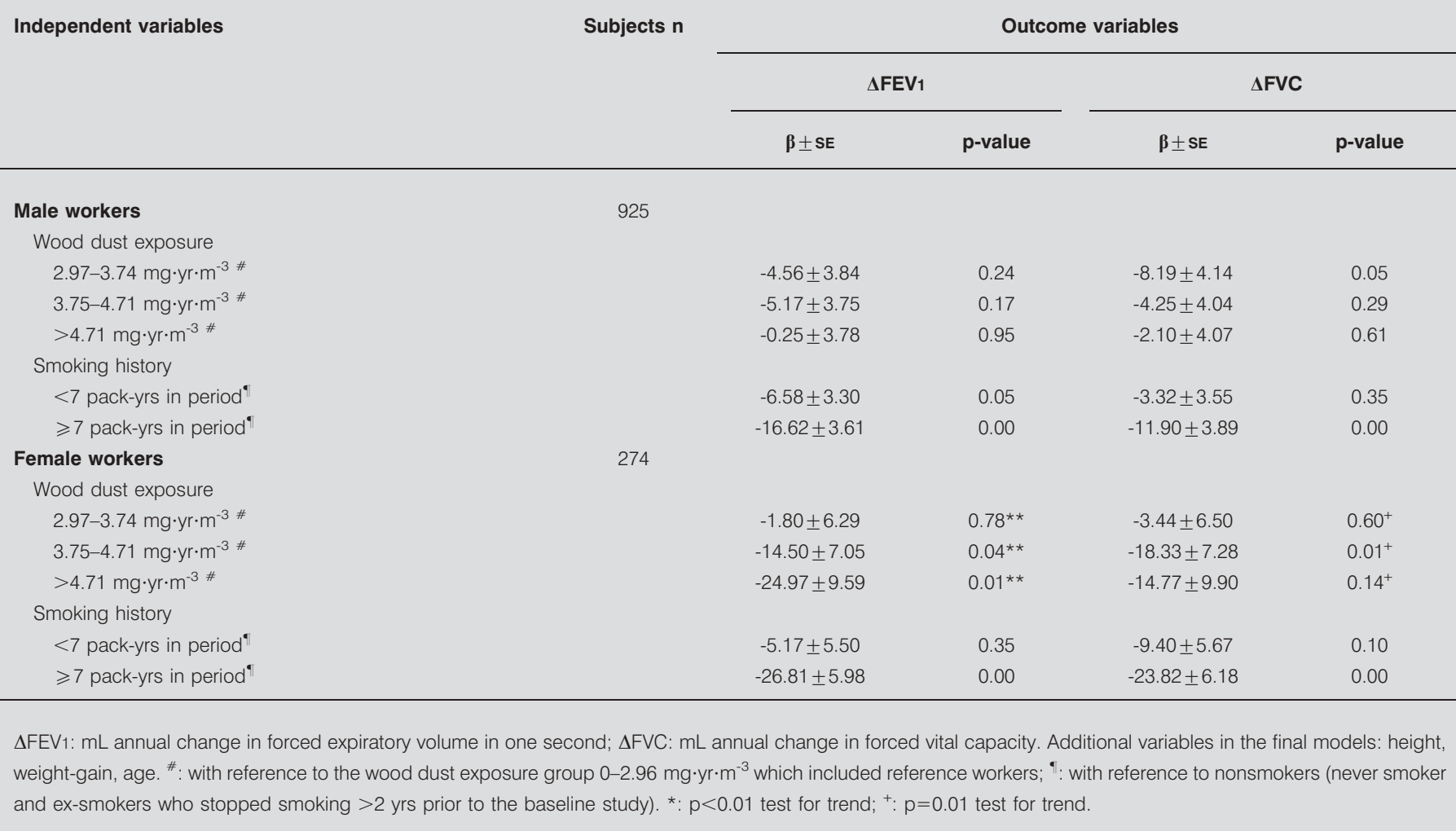

Analyses for association between cumulative exposure and relative changes in lung function were conducted, revealing associations similar to results given in tables 3 and 4 . When linear regression analyses, including cumulative exposure as a continuous variable, were performed, significant negative regression coefficients were found for absolute and relative

TABLE 5 Associations between changes in lung function and measures of exposure in the cohort, stratified by sex and adjusted for confounders in linear regression analyses

Independent variables $\#$
Subjects $n$
Outcome variables

\begin{tabular}{|c|c|c|c|}
\hline \multicolumn{2}{|c|}{$\Delta \mathrm{FEV}_{1}$} & \multicolumn{2}{|c|}{$\Delta F V C$} \\
\hline$\beta \pm S E$ & $p$-value & $\boldsymbol{\beta} \pm \mathrm{SE}$ & p-value \\
\hline
\end{tabular}

\section{Male workers}

Wood dust exposure baseline ${ }^{\boldsymbol{\tau}},+$

Years of woodworking in the follow-up period ${ }^{\text {, + }}$

Employed at follow-up ${ }^{+,} f$

Employed in wood industry at follow-up \#\#

Female workers

Wood dust exposure baseline ${ }^{+}$

Years of woodworking in the follow-up period ${ }^{+}$

Employed at follow-up ${ }^{+,} f$

Employed in wood industry at follow-up \#\#

$\begin{array}{lcr}951 & 6.06 \pm 3.35 & 0.07 \\ 938 & -0.51 \pm 0.65 & 0.44 \\ 823^{\S} & -10.35 \pm 4.34 & 0.02 \\ 629^{\text {ฯ }} & -11.11 \pm 3.26 & <0.01 \\ & & \\ 279 & -10.62 \pm 4.97 & 0.03 \\ 274 & -2.34 \pm 0.94 & 0.01 \\ 245^{++} & -11.13 \pm 7.79 & 0.16 \\ 112^{f f} & -16.15 \pm 3.33 & 0.03\end{array}$

0.19

0.39

$\begin{array}{ll}-11.74 \pm 4.67 & 0.01 \\ -8.58 \pm 3.54 & 0.02\end{array}$

$\begin{array}{ll}-11.74 \pm 4.67 & 0.01 \\ -8.58 \pm 3.54 & 0.02\end{array}$

$-9.61 \pm 5.15 \quad 0.06$

$-1.93 \pm 0.97 \quad 0.05$

$-7.74 \pm 7.78 \quad 0.32$
$-4.27 \pm 8.04 \quad 0.60$

$\triangle F E V_{1}: m L$ annual change in forced expiratory volume in one second; $\Delta \mathrm{FVC}: \mathrm{mL}$ annual change in forced vital capacity. ${ }^{\#}$ : variables included in all models were: age height, weight-gain and smoking information (nonsmokers were never smokers and ex-smokers who stopped smoking $>2$ yrs prior to the baseline study; smokers were stratified into $<7$ pack-yrs and $\geqslant 7$ pack-yrs during follow-up); ${ }^{\bullet}$ : analysed as a continuous variable; ${ }^{+}$: reference workers were included in the cohort analysed; ${ }^{f}$ : reference not employed at follow-up; ${ }^{\text {s: }}$ out of 939 total; ${ }^{\# \#}$ : reference not employed in wood industry at follow-up; ${ }^{\text {"ฯ }}$ : out of 848 total; ${ }^{++}$: out of 274 total; ${ }^{\text {ff: }}$ : out of 161 total. 


\begin{tabular}{|c|c|c|c|}
\hline TABLE 6 & \multicolumn{3}{|c|}{$\begin{array}{l}\text { Association between cumulative incidence proportion of forced expiratory volume in one second (FEV } 1) / \text { forced vital } \\
\text { capacity }(F V C)<70 \% \text { and wood dust exposure in the cohort, stratified by sex adjusted for confounders in logistic } \\
\text { regression analyses }\end{array}$} \\
\hline \multicolumn{2}{|c|}{ Independent variables } & $\mathrm{n} / \mathrm{N}(\%)$ & OR (95 \% Cl) \\
\hline \multicolumn{2}{|c|}{ Wood dust exposure $3.75-4.71 \mathrm{mg} \cdot \mathrm{yr} \cdot \mathrm{m}^{-3}$ \# } & $14 / 223(6.3)$ & $1.45(0.66-3.16)$ \\
\hline \multicolumn{2}{|c|}{ Wood dust exposure $>4.71 \mathrm{mg} \cdot \mathrm{yr} \cdot \mathrm{m}^{-3} \#$} & $12 / 219(5.5)$ & $1.39(0.61-3.15)$ \\
\hline \multicolumn{2}{|c|}{ Smokers } & 42/394 (10.7) & $6.15(3.03-12.48)$ \\
\hline \multicolumn{2}{|c|}{ Female workers } & $11 / 285(3.9)$ & \\
\hline \multicolumn{2}{|c|}{ Wood dust exposure 2.97-3.74 $\mathrm{mg} \cdot \mathrm{yr} \cdot \mathrm{m}^{-3}$ \# } & 2/51 (3.9) & $1.45(0.24-8.44)^{+}$ \\
\hline
\end{tabular}

changes of lung function indices for female workers. For annual change in FEV1, the regression coefficient was $-3.1 \mathrm{~mL} \cdot \mathrm{yr}^{-1}(\mathrm{p}=0.01)$ and for annual change in FVC, it was $-3.0 \mathrm{~mL} \cdot \mathrm{yr}^{-1}(\mathrm{p}=0.02)$. In addition, analyses performed excluding reference workers showed similar associations, although in general not reaching statistical significance.

Table 5 presents linear regression models of associations between decline in lung function and baseline wood dust exposure, years of woodworking in the follow-up period, job status at follow-up and woodworking status at follow-up; all stratified on sex and adjusted for smoking, age and weightgain during follow-up.

Analyses revealed a significant negative association between baseline exposure to wood dust as a continuous variable and annual change in FEV1 among female workers, and a borderline significant positive association for male workers (table 5).

Regression analyses of association between years of woodworking during follow-up and annual change in FEV1, revealed a significant negative association for female workers (table 5).

In addition, table 5 presents regression analyses of the associations between having a job at follow-up for all workers still being employed in the furniture industry for woodworkers and decline in lung function. For male workers, a larger decline in FEV1 and FVC was found for workers possessing a job and for male woodworkers still employed in the wood industry compared with workers not possessing a job and to woodworkers who had left the wood industry, respectively. For female woodworkers, a greater decline in FEV1 was found among workers still employed in the wood industry.

Adjusted linear regression analysis of association between cumulative exposure and decline in lung function indices among woodworkers stratified by sex and whether woodworkers had left the wood industry did not show significant associations between exposure and decline in lung function for woodworkers still employed in the wood industry, or for woodworkers who had left the industry. For male woodworkers still employed in the wood industry, significantly negative regression coefficients for change in FVC ranging from $-17.49--22.03 \mathrm{~mL} \cdot \mathrm{yr}^{-1}$ for exposure groups $>2.96 \mathrm{mg} \cdot \mathrm{yr} \cdot \mathrm{m}^{-3}$ compared with male woodworkers in the lowest exposure group were found.

After exclusion of all workers with an FEV1/FVC ratio $<70 \%$ at baseline, the overall cumulative incidence proportion of FEV1/FVC $<70 \%$ in the follow-up period was $5.82 \%$ for woodworkers and $3.18 \%$ for reference workers.

In multiple logistic regression stratified by sex and adjusting for smoking and age, female workers had increasing odds ratios across exposure groups compared with non-/low-exposed female workers (nonsignificant) with odds ratio ranging 1.453.86 (table 6). A test for trend was nonsignificant $(p=0.08)$.

\section{DISCUSSION}

To the authors' knowledge, the present study is the first follow-up study in the dry wood industry that investigates the association between wood dust exposure and decline in lung function. The present results suggest that females, but not males, have an accelerated decline in lung function in a cohort exposed to relatively low concentrations of wood dust. An accelerated annual decline in FEV1 was found among female woodworkers, most pronounced for smokers, compared with female reference workers. A dose-response relationship between cumulative wood dust exposure and annual decline in FEV1 was suggested for female workers, and this was confirmed in a linear regression model adjusting for relevant confounders. In addition, dose-response relationships between baseline exposure to wood dust, years of woodworking during follow-up and annual decline in FEV1 were revealed for female workers. For females, a positive trend between wood dust 
exposure and the cumulative incidence proportion of FEV1/ FVC $<70 \%$ was suggested $(\mathrm{p}=0.08)$.

No association was found between wood dust concentration level or seniority in the wood industry and baseline lung function parameters in the baseline study [9]. In other studies [3, $10]$, relationships between wood dust exposure and decline in lung function have been revealed, especially among sawmill workers. Sawmill workers exposed to western red cedar were studied in an 11-yr follow-up study including 243 subjects [3]. Workers were divided into groups with mean average exposure between $<0.2$ and $>0.4 \mathrm{mg} \cdot \mathrm{m}^{-3}$. A dose-response relationship between exposure and annual decline in FEV1 and FVC was found. Another follow-up study among 280 male workers with red cedar asthma reported that patients who continued to be exposed had a greater decline in FEV1 compared with exposed workers without red cedar asthma [10].

In the dry wood industry, cross-sectional studies using cumulative exposure indexes or years of employment have reported conflicting results, although most studies find an effect of wood dust exposure on lung function decline. In a study of joineries and sawmills, MANDRYK et al. [4] found that woodworkers had decreased lung function compared with controls, and that the effect of personal exposure was most pronounced among joinery workers. In contrast, it was found that percentage predicted lung function was positively correlated with the numbers of years of exposure to wood dust, which was explained by healthy worker selection.

Among furniture workers using mainly oak, aspen and pine, CAROSSO et al. [21] found a dose-response relationship between years of employment (mean $25 \mathrm{yrs}$ ) and decrease in FEV1. Among workers exposed to pine and medium density fibreboard, SHAMSSAIN et al. [2] revealed a dose-response relationship between duration of employment and decreased FVC and FEV1/FVC.

HOLNESS et al. [22] presented a dose-response relationship between decreased FEV1 and an exposure time index for furniture workers exposed to medium density fibreboard. In a study of furniture workers exposed to softwoods, WHITEHEAD et al. [23] reported a dose effect of cumulative exposure and a reduced ratio of FEV1/FVC to both hardwood and softwood.

In a study of beach and oak workers with a high median cumulative exposure of $110 \mathrm{yrs} \mathrm{mg} \cdot \mathrm{m}^{-3}$, BOHADANA et al. [7] did not reveal any differences in FVC, FEV1 or FEV1/FVC. Similarly, BORM et al. [8] found no association between lung function indices and cumulative exposure in a study on 982 woodworkers exposed to Marasi wood.

Overall participation rate in the follow-up study was $60 \%$, which may have caused selection bias. The dropout analyses showed a greater participation rate for both woodworkers and reference workers among those contacted at the factories, in comparison with subjects invited by letter (fig. 1). This indicates that a greater proportion of people who had left the industry did not have the same inducement to participate. This may contribute to a healthy worker selection in the cohort, as individual experiencing respiratory symptoms might be more prone to leave the industry.
Participants were slightly older and smoked less than nonparticipants. However, no difference was found in baseline respiratory symptoms or baseline lung function indicating chronic bronchitis or impaired lung function between participants and nonparticipants or between woodworkers invited to participate at the factories and woodworkers invited to participate outside the industry. In addition, no significant difference in the participation rate between woodworkers and reference workers was found. Analyses were stratified by sex and adjusted for relevant confounders, including smoking. Hence, it is unlikely that selection bias had a major influence on the results.

The measured inhalable wood dust concentrations in the present study were low, with a geometric mean of $0.94 \mathrm{mg} \cdot \mathrm{m}^{-3}$ at baseline and $0.60 \mathrm{mg} \cdot \mathrm{m}^{-3}$ at follow-up. It has recently been estimated that 560,000 workers in the European Union may be exposed to a level $>5 \mathrm{mg} \cdot \mathrm{m}^{-3}$ and that a concentration of $2 \mathrm{mg} \cdot \mathrm{m}^{-3}$ may be exceeded by 2 million workers [1]. This suggests that the Danish furniture industry is in the very low end of the wood dust exposure distribution in Europe.

The aim of the present study study was to report relationships between cumulative wood dust exposure and loss of lung function measured as decline in FEV1, FVC, and the cumulative incidence proportion of FEV1/FVC $<70 \%$ as "red flags" for risk of chronic obstructive pulmonary disease (COPD). Individuals were assigned values of exposure at baseline and follow-up from study-specific job-exposure matrices based on a large number of personal dust measurements. As a consequence, each exposure estimate was based on a large number of samples, which minimised the risk of attenuation bias [24].

There is debate concerning the use of $70 \%$ as the cut-off point for risk of COPD as this has a tendency to overestimate COPD with increasing age $[25,26]$. However, for the relatively young group of workers in the present study, this problem probably only marginally influenced the interpretation.

The present results indicate that females are more susceptible to wood dust exposure than males. In the baseline study [9], a positive interaction between female gender and high dust exposure for self-reported asthma has been found. In addition, females, but not males, had increasing prevalence of chronic bronchitis with increasing seniority in the furniture industry. A greater susceptibility among females is known in other settings, notably for tobacco use. Females seem to be more predisposed to develop COPD at an earlier age, and with a larger impairment in lung function for a given amount of tobacco exposure. The mechanism behind females being more vulnerable to tobacco smoke may be a consequence of smaller airway size [27]. MATHESON et al. [28] calculated cumulative exposure years for biological dust, mineral dust, gas and fumes based on a jobexposure matrix, and they found significant associations between exposure to biological dust and chronic obstructive bronchitis, emphysema and COPD in females, but not in males. For COPD, the interaction with sex was statistically significant. In a 9-yr population-based follow-up study, SUNIER et al. [29] revealed a larger decline in FEV1 among females exposed to high levels of both biological and mineral dust.

Do the present findings have any clinical relevance? As indicated in table 2, female smokers not exposed to wood 
dust experience a mean annual decrease in FEV1 of $23.5 \mathrm{~mL}$, whereas female wood workers exposed to wood dust have an annual decrease of $37.0 \mathrm{~mL}$. In a 30 -yr work period this would account for an additional loss of $405 \mathrm{~mL}$ on top of loss of lung function accounted for by smoking and age. Although smoking is clearly affecting decrease in lung function on a greater scale than wood dust, the effect of wood dust exposure is not without clinical significance.

In conclusion it was found that females, but not males, have an accelerated decline in lung function during a 6 year follow-up in the Danish furniture industry. As this is a relatively low exposed cohort and dust exposure in the industry has decreased significantly in the follow-up period, this might indicate that wood dust could cause an important clinical reduction in lung function.

\section{REFERENCES}

1 Kauppinen T, Vincent R, Liukkonen T, et al. Occupational exposure to inhalable wood dust in the member states of the European Union. Ann Occup Hyg 2006; 50: 549-561.

2 Shamssain MH. Pulmonary function and symptoms in workers exposed to wood dust. Thorax 1992; 47: 84-87.

3 Noertjojo HK, Dimich-Ward H, Peelen S, Dittrick M, Kennedy SM, Chan-Yeung M. Western red cedar dust exposure and lung function: a dose response relationship. Am J Respir Crit Care Med 1996; 154: 968-973.

4 Mandryk J, Alwais KU, Hocking AD. Work-related symptoms and dose-response relationships for personal exposures and pulmonary function among woodworkers. Am J Ind Med 1999; 35: 481-490.

5 Talini D, Monteverdi A, Benvenuti A, et al. Asthma-like symptoms, atopy, and bronchial responsiveness in furniture workers. Occup Environ Med 1998; 55: 786-791.

6 Ahman M, Persson L, Lagerstrand L, Söderman E, Cynkier I. Lung function in woodworking teachers in Sweden. Int J Occup Environ Health 1996; 2: 204-210.

7 Bohadana AB, Massin N, Wild P, Toamain JP, Engel S, Goutet P. Symptoms, airway responsiveness, and exposure to dust in beech and oak wood workers. Occup Environ Med 2000; 57: 268-273.

8 Borm PJ, Jetten M, Hidayat S, et al. Respiratory symptoms, lung function, and nasal cellularity in Indonesian wood workers: a dose-response analysis. Occup Environ Med 2002; 59: 338-344.

9 Schlünssen V, Schaumburg I, Taudorf E, Mikkelsen AB, Sigsgaard T. Respiratory symptoms and lung function among Danish woodworkers. J Occup Environ Med 2002; 44: 82-98.

10 Lin FJ, Dimich-Ward H, Chan-Yeung M. Longitudinal decline in lung function in patients with occupational asthma due to western red cedar. Occup Environ Med 1996; 53: 753-756.

11 Jacobsen G. Respiratory diseases and exposure in the Danish Furniture Industry: A 6 year follow-up. PhD thesis. Faculty of Health Sciences, University of Århus, Århus, Denmark, 2007.

12 Vinzents PS. A passive personal dust monitor. Ann Occup Hyg 1996; 40: 261-280.
13 Schlünssen V, Vinzents PS, Mikkelsen AB, Schaumburg I. Wood dust exposure in the Danish furniture industry using conventional and passive monitors. Ann Occup Hyg 2001; 45: 157-164.

14 Schlünssen V, Sigsgaard T, Schaumburg I, Kromhout H. Cross-shift changes in FEV1 in relation to wood dust exposure: the implications of different exposure assessment methods. Occup Environ Med 2004; 61: 824-830.

15 Definition and classification of chronic bronchitis for clinical and epidemiological purposes. A report to the Medical Research Council by their Committee on the Aetiology of Chronic Bronchitis. Lancet 1965; 1: 775-779.

16 Burney PG, Luczynska C, Chinn S, Jarvis D. The European Community Respiratory Health Survey. Eur Respir J 1994; 7: 954-960.

17 Quanjer PH, Tammeling GJ, Cotes JE, Pedersen OF, Peslin R, Yernault JC. Lung volumes and forced ventilatory flows. Report Working Party Standardization of Lung Function Tests, European Community for Steel and Coal. Official Statement of the European Respiratory Society. Eur Respir J Suppl 1993; 16: 5-40.

18 Danish Lung Association. Spirometry. A recommendation. [Spirometri - En reckommandation fra Dansk Lungemedicinsk Selskab.] Copenhagen, Danish Lung Association, 1996.

19 Omland O, Sigsgaard T, Hjort C, Pedersen OF, Miller MR. Lung status in young Danish rurals: the effect of farming exposure on asthma-like symptoms and lung function. Eur Respir J 1999; 13: 31-37.

20 Cantani A, Ferrara M, Barbieri C, Monteleone A, Businco L. Evaluation of new test (Phadiatop) for the screening of respiratory allergic disorders in children. Ann Allergy 1990; 64: 158-161.

21 Carosso A, Ruffino C, Bugiani M. Respiratory diseases in wood workers. Br J Ind Med 1987; 44: 53-56.

22 Holness DL, Sass-Kortsak AM, Pilger CW, Nethercott JR. Respiratory function and exposure-effect relationships in wood dust-exposed and control workers. J Occup Med 1985; 27: 501-506.

23 Whitehead LW, Ashikaga T, Vacek P. Pulmonary function status of workers exposed to hardwood or pine dust. Am Ind Hyg Assoc J 1981; 42: 178-186.

24 Tielemans E, Kupper LL, Kromhout H, Heederik D, Houba R. Individual-based and group-based occupational exposure assessment: some equations to evaluate different strategies. Ann Occup Hyg 1998; 42: 115-119.

25 Hardie JA, Buist AS, Vollmer WM, Ellingsen I, Bakke PS, Mørkve O. Risk of over-diagnosis of COPD in asymptomatic elderly never-smokers. Eur Respir J 2002; 20: 1117-1122.

26 Hansen JE, Sun XG, Wasserman K. Spirometric criteria for airway obstruction: Use percentage of FEV1/FVC ratio below the fifth percentile, not $<70 \%$. Chest 2007; 131: 349-355.

27 Chapman KR. Chronic obstructive pulmonary disease: are women more susceptible than men? Clin Chest Med 2004; 25: 331-341.

28 Matheson MC, Benke G, Raven J, et al. Biological dust exposure in the workplace is a risk factor for chronic obstructive pulmonary disease. Thorax 2005; 60: 645-651.

29 Sunyer J, Zock JP, Kromhout H, et al. Lung function decline, chronic bronchitis, and occupational exposures in young adults. Am J Respir Crit Care Med 2005; 172: 1139-1145. 